\title{
Polymer Science, From Academic to All
}

\author{
Cheng Chen* \\ School of Environmental and Materials Engineering, College of Engineering, Shanghai Polytechnic University, Shanghai, China
}

Submission: May 28, 2018; Published: May 31, 2018

*Corresponding author: Cheng Chen, School of Environmental and Materials Engineering, College of Engineering, Shanghai Polytechnic University, China, Email: chencheng@sspu.edu.cn

\section{Editorial}

For over a century, polymer science has experienced many important developments, and many achievements have been made on the basis of theoretical and empirical research. Polymers have unique properties such as high strength, toughness and elasticity due to their intermolecular behavior causing by the large molecular weight and long molecular chain, which are very different from those of small molecules. Polymer compounds are ubiquitous in nature, including the protein and cellulose that make up the organism, nucleic acids that carrying biological genetic information, and raw materials of clothes such as cotton, wool and silk. On the other hand, synthetic polymers play an important role in polymer science. Such kinds of polymers are produced from small molecules via polyaddition or poly-condensation method. Nowadays, polymers are indispensable in people's life, and the researches aimed at solving scientific problems as well as particle applications needs to be strengthened, with emphasis on spreading academic reporting articles to the public.

Academic Journal of Polymer Science (AJOP) is a new interdisciplinary, Open Access scientific journal focus on polymer science from Juniper Publishers. This journal welcomes all types of manuscript submissions like Research, Review, MiniReview, Opinion, Short Communication, Case Report etc. Both fundamental theory and experimental research and application

are welcomed. AJOP covers the research areas of particular interest, including biomedical applications, organic electronics and photonics, nanostructures, micro- and nano-fabrication, biological molecules (DNA, proteins, carbohydrates), polymers for renewable energy and ozone, atmospheric pollutants, mechanical stress, biological action, hydrolysis and many other influences, potential industrial application in areas such as food, textiles, paper, wood, adhesives, biodegradables, bio refining, pharmaceuticals, and oil recovery, exchange of research in the area of macromolecular substances, both synthetic and natural polymers. Manuscripts will be ensured by a rigorous peerreview procedure, followed by rapid publication, if accepted.

All the published manuscript in AJOP will immediately accessible worldwide under an Open Access license. One could read the full-text of all articles published in AJOP, including related scientists and the general public. This means that the scientific work from academic is open to all, and also, the work will be influential. Open Access publication is commonly supported by the payment of Article Processing Charges (APC) from the authors' research budget.

I hope that AJOP will establish a community of scientists working in polymer science and associated areas, as the discipline barriers and important discipline problems might be solved.
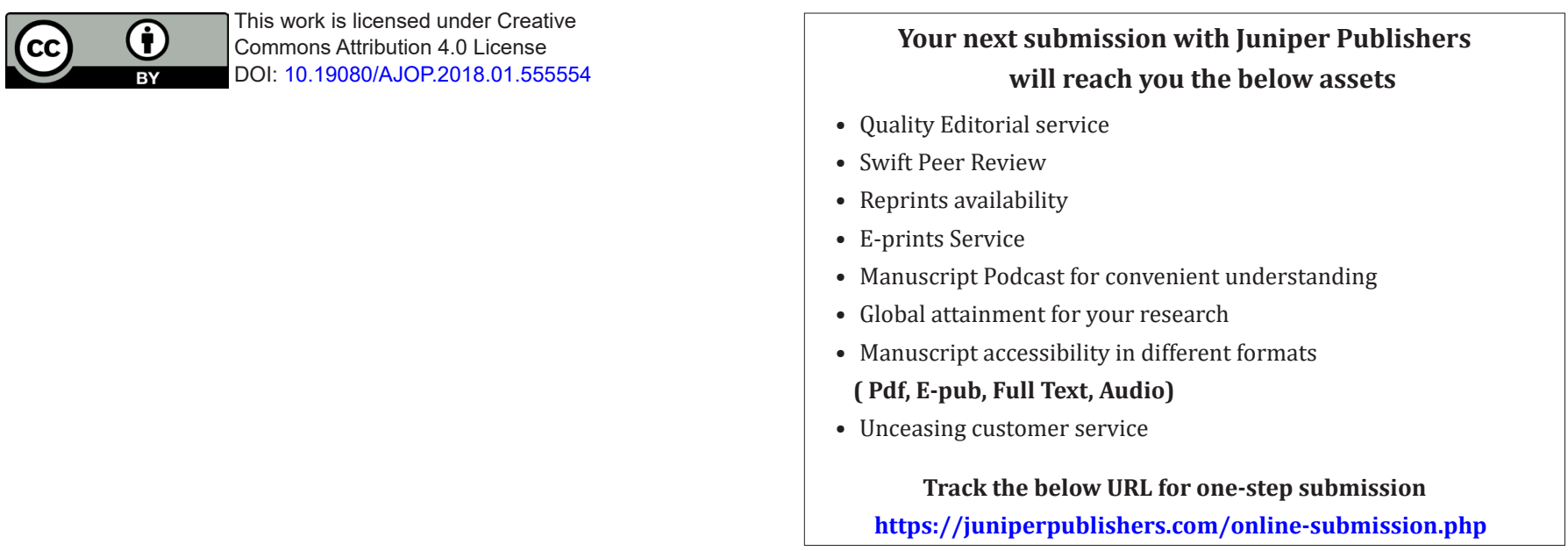